\title{
Transforming industrial food systems to prevent future disruptions
}

\author{
Review by Laxmi Prasad Pant, Natural Resources Institute, \\ University of Greenwich*
}

Review of Organic Food and Farming in China: Top-down and Bottom-up Ecological Initiatives, by Steffanie Scott, Zhenzhong Si, Theresa Schumilas, and Aijuan Chen. (2018). Routledge. Available as ebook, hardcover, and paperback; 236 pages. Publisher's website: https://www.taylorfrancis.com/books/e/9780203701706

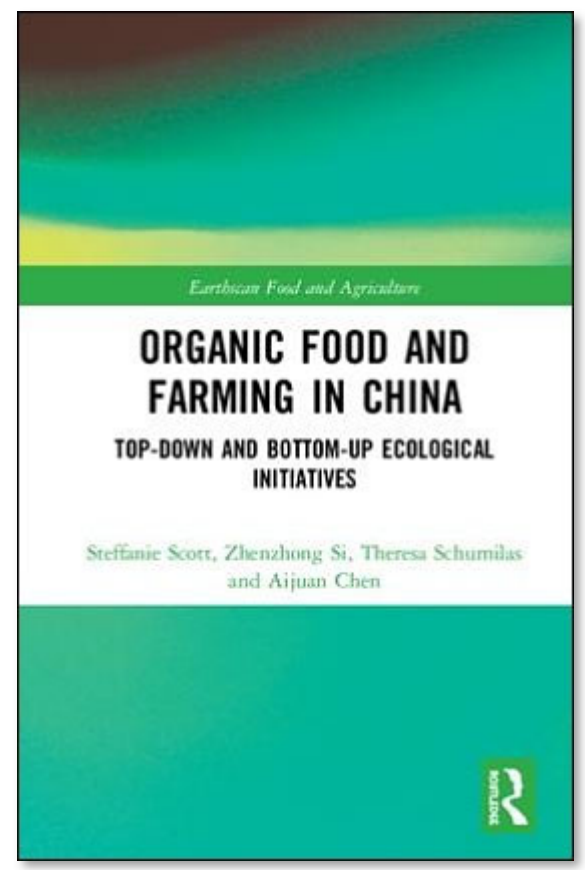

Submitted June 15, 2020 / Published online August 4, 2020

Citation: Pant, L. P. (2020). Transforming industrial food systems to prevent future disruptions [Book review]. Journal of Agriculture, Food Systems, and Community Development, 9(4), 331-333. https://doi.org/10.5304/jafscd.2020.094.023

Copyright (C) 2020 by the Author. Published by the Lyson Center for Civic Agriculture and Food Systems. Open access under CC-BY license.

I cannot emphasize enough the relevance of the work reported in this book, most notably how Chinese consumers procure food, including socalled wet markets that are often blamed for infectious disease outbreaks (e.g., SARS-CoV in 2002 and SARS-CoV-2 in 2019). For this reason, JAFSCD has allowed me to review this book although it was ably reviewed by Anthony Fuller in the previous issue of JAFSCD (Fuller, 2020). This book provides theoretical as well as empirical analysis of food systems in China, a country with

\footnotetext{
* Laxmi Prasad Pant, Ph.D., Senior Lecturer and Researcher of Human Geography and Food Systems, Natural Resources Institute, University of Greenwich; Central Avenue; Chatham Maritime, Kent ME4 4TB, UK; L.P.Pant@greenwich.ac.uk
}

the largest human population. It also details the long-established history of how traditional wet markets have become culturally important for food, nutrition, health, livelihoods, and wellbeing of Chinese residents. The book is divided into 10 self-contained chapters. Chapter 1 introduces the topic with a compelling story of how the authors' journey to write this book began after they attended the BioFach China trade fair in Shanghai, the biggest annual organic food trade fair in the country (http://www.biofachchina.com/en/). This chapter also outlines the research objectives and methods for data collection and analysis. Chapter 2 provides further context surrounding China's changing food systems after the economic liberalization in the late 1970 s, following the death of 
Mao Zedong, former chairman of the People's Republic of China. It was the time when industrial agriculture gained momentum in the country. Together with crop monoculture that eroded agricultural biodiversity and polluted air, water, and soil, industrial livestock production led to the concentration of animal wastes and excessive use of antibiotics and growth hormones.

Subsequently, chapters 3 and 4 provide empirical evidence on the state-led promotion of food systems that offer alternatives to industrial food systems, and chapter 5 discusses bottom-up grassroots initiatives. Farmers markets, often labeled as organic markets in China, provide alternative market spaces for emerging middle-class customers who can pay a premium price for the perceived quality and safety of agricultural products sold in these markets. Food prices are lower in China's supermarkets and traditional wet markets than in farmers markets. Chapter 7 presents a case study of the Beijing Organic Farmers' Market to illustrate how such markets serve as contested spaces. The remaining chapters (chapters 6,8 , and 9) cover the cross-cutting issues of agricultural and rural development in China, and the final chapter (chapter 10) concludes the book with a reflection on the development of alternative food systems and agrarian movements in China.

The remainder of this review focuses on the three types of food markets in China: modern supermarkets, traditional wet markets, and farmers markets. It further discusses the implications of these markets on building resilience and transforming food systems to avoid future disruptions from sudden shocks as well as gradual stresses.

\section{Modern Supermarket}

The term "supermarketization" is used five times in the book, primarily to discuss how the global trend of bigger, faster, cheaper, and standardized food products co-exist with China's traditional food systems, often with tensions and contestations based on beliefs and values of either system. A recent study by some of the same authors ( $\mathrm{Si}$, Scott, \& McCordic, 2019) documents that supermarkets in Nanjing, the capital of China's eastern Jiangsu province, normally sell rice, dairy, eggs, pasta, noodles, cooking oil, sugar, white bread, brown bread, tea, snacks, coffee, sweets, chocolate, potato chips, French fries, canned vegetables, frozen pork, canned fruit, frozen beef, frozen lamb, cooked lamb, frozen shellfish, and canned meat. This mode of marketing is based on the principle of a "just enough, just in time" food supply that depends on standardized and homogeneous products sourced from the monoculture of crops, livestock, poultry, and aquatic species.

\section{Traditional Wet Market}

The book reveals that despite the expansion of supermarkets, most Chinese consumers continue to purchase foods in traditional wet markets. Food items more commonly acquired in these markets are fresh fruits and vegetables; raw pork, chicken, fish, beef, lamb, shellfish and offal; frozen fish and chicken; cooked pork, chicken, beef and shellfish; and steamed bread and patty, sowbow, pies, and samosas (Si, Scott, \& McCordic, 2019). The name "wet market" appears five times in the book to illustrate why traditional markets still exist. Wet markets are diverse in form, contrary to international media portrayals of these markets as homogenous spaces with food safety, quality, and animal welfare concerns (T. Zhong, Si, Crush, Scott, \& Huang, 2019). Furthermore, a study in southern China, specifically Sanya in Hainan province and Guangzhou in Guangdong province, concludes that the cultural construction of freshness creates a niche for small-scale traders in traditional wet markets (S. Zhong, Crang, \& Zeng, 2020). The proportion of households with food and nutrition security is $79 \%$ in Nanjing, which is attributed to access to traditional wet markets (Zhong et al., 2019). The industrial modernization of agriculture has pushed regionally oriented traditional food markets to the margins, partly because of the perceived food safety issues and adoption of the modern, fast lifestyle. Until the 1980s, most wet markets were informal street food vending operations, but starting in the 1990s, local governments regulated these markets by building closed, usually in indoor, spaces (T. Zhong \& Scott, 2020). Farmers markets are sometimes considered as a viable alternative that would continue the gambit of traditional markets while addressing the perceived food safety issues. 


\section{Alternative Farmers Market}

The book further notes that in contrast to traditional wet markets, where petty traders also bring products from large wholesale markets for resale, at farmers markets producers themselves participate, although there are many exceptions. Farmers market venders also are not necessarily primary producers and traditional growers whose lives and livelihoods are dependent on agriculture. In this type of direct marketing, producers and consumers interact, often inviting the latter to visit farms. By way of comparison of farmers markets in industrialized countries, this book explains that Chinese farmers markets exclude customers who cannot pay a premium price for the perceived quality and safety of the produce being offered.

This book serves as an excellent resource for those who are interested in food systems resilience, robustness, and sustainability. However, it is missing an examination of problems with current animal protein sources, including industrial food animal production, live animal transport and sale, and illegal wild animal trade (Greger, 2007). As such, over 65 billion broiler chickens are slaughtered per year worldwide; the combined mass of these birds exceeds all other birds on Earth, and they are unable to survive and reproduce without human intervention (Bennett et al., 2018). The current pandemic exposed the fault lines of the industrial food system, including the unfortunate burying alive of millions of young broiler chickens, plowing under of vegetables, and dumping of milk, all due to disruptions in the supply chain (Clapp, 2020).

The pandemic provides an opportunity to transform the industrial food system in China and around the world. It could be a mistake to push regionally oriented traditional food systems to the margins or, worse, to shut them down. Such an attempt to modernize food systems can severely affect millions of lives and livelihoods. Although it may appear counterintuitive, government bodies in China, in their efforts to adapt to the postpandemic food environment, temporarily relaxed street food vending regulations to achieve the twin goals of creating employment for low-income households in the informal sector while promoting food security (T. Zhong \& Scott, 2020). The regulation and standardization of traditional food systems out of concern for quality and safety should differentiate wet meat markets and fresh fruit and vegetable markets, specifically in deciding the fate of Chinese wet markets in a postpandemic world.

\section{References}

Bennett, C. E., Thomas, R., Williams, M., Zalasiewicz, J., Edgeworth, M., Miller, H., . . Marume, U. (2018). The broiler chicken as a signal of a human reconfigured biosphere. Royal Society Open Science, 5(12), 180325.

http://doi.org/10.1098/rsos.180325

Clapp, J. (2020, May 8). Spoiled milk, rotten vegetables, and a very broken food system. The New York Times. Retrieved from https://nyti.ms/3fvJzYh

Fuller, A. M. (2020). An in-depth look at Chinese alternative food networks. Journal of Agriculture, Food Systems, and Community Development, 9(3), 321-323. https://doi.org/10.5304/jafscd.2020.093.008

Greger, M. (2007). The human/animal interface: Emergence and resurgence of zoonotic infectious diseases. Critical Reviews in Microbiology, 33(4), 243-299. https://doi.org/10.1080/10408410701647594

Si, Z., Scott, S., \& McCordic, C. (2019). Wet markets, supermarkets and alternative food sources: Consumers' food access in Nanjing, China. Canadian Journal of Development Studies, 40(1), 78-96. https://doi.org/10.1080/02255189.2018.1442322

Zhong, S., Crang, M., \& Zeng, G. (2020). Constructing freshness: The vitality of wet markets in urban China. Agriculture and Human Values, 37, 175-185. https://doi.org/10.1007/s10460-019-09987-2

Zhong, T., \& Scott, S. (2020). "Informalization" of food vending in China: From a tool for food security to employment promotion. Journal of Agriculture, Food Systems, and Community Development. Advance online publication. https://doi.org/10.5304/jafscd.2020.094.006

Zhong, T., Si, Z., Crush, J., Scott, S., \& Huang, X. (2019). Achieving urban food security through a hybrid public-private food provisioning system: The case of Nanjing, China. Food Security, 11, 1071-1086. https://doi.org/10.1007/s12571-019-00961-8 